Article

\title{
Evaluation of Preferences for Alternative Transportation Services and Loyalty towards Active Transportation during a Major Transportation Infrastructure Disruption
}

\author{
Nazmul Arefin Khan ${ }^{1}$ and Muhammad Ahsanul Habib ${ }^{2, * \text { (D) }}$ \\ 1 Department of Civil and Resource Engineering, Dalhousie University, 1360 Barrington Street, \\ PO Box 15000, Halifax, NS B3H 4R2 Canada; nazmul.arefin@dal.ca \\ 2 School of Planning and Department of Civil and Resource Engineering, Dalhousie University, \\ 5410 Spring Garden Road, Halifax, NS B3H 4R2 Canada \\ * Correspondence: ahsan.habib@dal.ca; Tel.: +1-902-494-3209
}

Received: 25 May 2018; Accepted: 15 June 2018; Published: 16 June 2018

\begin{abstract}
This paper investigates active transportation mode users' preferences for alternative services during the temporary closure event of a bridge and its active transportation (AT) lanes. It also evaluates the loyalty of AT users during the event. The study uses data from a travel survey distributed to cyclists and pedestrians, who are the regular AT lane users of the Macdonald Bridge in Halifax, Canada. Random parameter logit models are developed in this study that examine the effects of socio-demographic, travel and neighborhood characteristics on active transportation users' preferences. Four alternative transportation services are considered in this study: free shuttle services, frequent ferry services, frequent bus services and other services. Results suggest that higher-income individuals are more likely to prefer frequent ferry services during the AT lane closure event. Transit commuters are found to prefer frequent bus services. Probability of preferring free shuttle services increases if individuals use AT lanes for cost savings. Loyalty towards AT is explored in this study by means of anticipated modal shift. For instance, higher mixed land use area dwellers tend to be loyal towards AT during the disruption event, as demonstrated by their lower probability to shift from current AT mode. This study offers critical behavioral insights, which would assist transportation planning and policies that aim to adopt sustainable transportation planning measures to retain current users' loyalty towards active transportation and prevent a long-term behavioral shift.
\end{abstract}

Keywords: active transportation; major transportation infrastructure disruption; alternative transportation services; transport loyalty; random parameter logit model

\section{Introduction}

Closure of major transportation infrastructures for an extended period incurs economic loss and causes long-term behavioral shifts that hamper the development of sustainable transportation planning of a region [1]. Critical transportation infrastructures, such as bridges, facilitate people and goods' movement efficiently across regions and have a significant influence on traffic patterns as well as travel behavior. Generally, bridges serve multiple purposes, such as connecting local road networks of adjacent cities with highway corridors. Much of the previous research on travel behavior due to major transportation network disruption examines the effects of bridge collapse incident on vehicular network [2-4]. Studies exist on travelers' responses in terms of auto and transit usage due to complete bridge closure [5] and partial bridge closure [6]. Also, studies that focus on evaluating the impacts of sudden natural disasters on travelers' behavior is evident in the 
existing literature [7]. Bridges are sometimes built with active transportation (AT) lanes that provide services to the cyclists and pedestrians, for instance, Port Mann Bridge (British Columbia, Canada) and George Washington Bridge (New Jersey, USA). Such facilities not only offer a variety of sustainable transportation alternatives, but also reduce personal vehicle usage and traffic congestion across the bridge, which in turn contribute in less vehicular emission and energy consumption.

Disruption of an active transportation lane due to major road network closure affects vulnerable population group [8]. Such event might also increase vehicle kilometers traveled across the road network that could rise daily emission. Notwithstanding these facts, how the associated active transportation lane disruption during a critical transportation infrastructure's temporary closure event for an extended period influences its users' travel behavior is not evident in the existing literature. From policy perspective, it is essential to understand users' preference for alternative transportation services during such disruption event since this requires providing alternative ways to cross the bridge. Active transportation plays a crucial role in a sustainable transportation planning agenda, hence, understanding the long-term effects an active transportation mode disruption event may incur is critical. Therefore, this study first explores cyclists and pedestrians' preference for alternative transportation services during the AT lane closure of a major transportation infrastructure. After that, to examine the long-term effects, a modal shift model is developed that evaluates the loyalty of cyclists and pedestrians towards using active transportation modes during the closure event. Methodologically, this study contributes to the existing literature by accommodating the preference variations across population, which is accomplished by developing random parameter logit models. This study utilizes datasets from an active transportation travel survey to assess the potential impacts on active transportation mode users.

\section{Literature Review}

A network disruption, such as bridge collapse, could affect its immediate vicinity as well as the entire city road network [9]. Commuters living closest to the disruption area are the most affected group in terms of their travel behavior [2]. Their route selection, destination choice, departure time, and travel scheduling face a greater variability during a network disruption event [3]. As a result, travel demand reduces due to frequent mode change and trip cancellation [10]. Network disruption could be caused by natural disasters (e.g., earthquakes) that sometimes create a greater impact by changing the length and accessibility of the network and declining the performance of the transportation system [11]. Researchers found that bridge collapse after an earthquake causes significantly higher traffic volume in the existing network compared to the pre-earthquake volume [7], which results in reduced system performance and greater economic loss $[1,12,13]$. A network disruption could also occur by pre-planned or unplanned special events. Pre-planned special events cause interruptions due to increasing traffic volume in a traffic network. Higher demand during such special events results in significantly higher public transit demand [14,15]. On the other hand, unplanned special events (e.g., transit strikes) increase reliance on personal vehicle use, thus increase congestion and cause network disruption [16]. Such events decrease transit ridership and often result in a permanent modal shift from transit to other modes available in the traffic network [17]. In summary, existing literature on major transportation network disruption primarily focuses on how disturbance in a network influences the overall travel demand, and changes network capacity and performance, among others.

Majority of the previous studies analyze travelers' responses to network disruption caused by sudden events (e.g., natural disasters) and shorter term special events. However, evaluating individuals' mobility decisions due to a major network disruption for an extended period is not evident in the previous studies, specifically in relation to sustainable active transportation usage. When faced with such events, it is essential to understand how users of a major transportation network choose their alternative transportation arrangement. In addition to that, examining the event's impact on loyalty to the existing mode is critical, particularly if it is a sustainable mode of transportation, such as walking, cycling and transit. Few studies exist that explored passenger loyalty towards public 
transit in terms of service quality while using transit daily [18-20]. Although pedestrians and cyclists (i.e., active transportation users) are often considered vulnerable due to the increased disutility incurred from disruptions [21], to the authors' knowledge, there is no existing study that explores loyalty of pedestrians and cyclists during a major transportation network's temporary closure.

Therefore, this study contributes to the existing literature in two ways: (1) evaluating preferences for alternative services that would facilitate active transportation usage during a network disruption event; and (2) investigating users' loyalty towards active transportation with respect to intended modal shift. An active transportation travel survey is used in this study that was conducted on the Macdonald Bridge active transportation lane users in Halifax, Canada. Random parameter logit (RPL) modeling technique is applied in this study to understand active transportation users' alternative service preferences and loyalty towards walking and cycling. The models incorporate taste preference variations (i.e., unobserved heterogeneity) across the sample population, and explore the impacts of various socio-demographic, travel and neighborhood attributes on pedestrian and cyclists' travel behavior during a major transportation infrastructure disruption event.

\section{Data}

\subsection{Macdonald Bridge Renewal Project: Survey of Cyclists and Pedestrians}

The paper uses data from the 'Macdonald Bridge Renewal Project: Survey of Cyclists and Pedestrians', which was conducted in Halifax, Nova Scotia, Canada. The Macdonald Bridge is a critical transportation network crossing Halifax Harbor in Nova Scotia that connects the twin cities, Halifax and Dartmouth (Figure 1). The bridge was opened on 2 April 1955. It is $1.30 \mathrm{~km}$ long and $11.50 \mathrm{~m}$ wide. There are three traffic lanes on the bridge with the center lane being reversible during the peak periods to assist the heavy traffic flow. One of the unique features of the bridge is that it provides active transportation facilities through two exclusive lanes on both sides. There are multiple toll stations at the Dartmouth side of the bridge. Although initially active transportation lane users had to pay tolls while crossing the bridge, later it was made toll-free to encourage more sustainable transportation usage. The bridge went on a renewal process in 2015, for which the active transportation lanes were removed from both sides for an extended period.

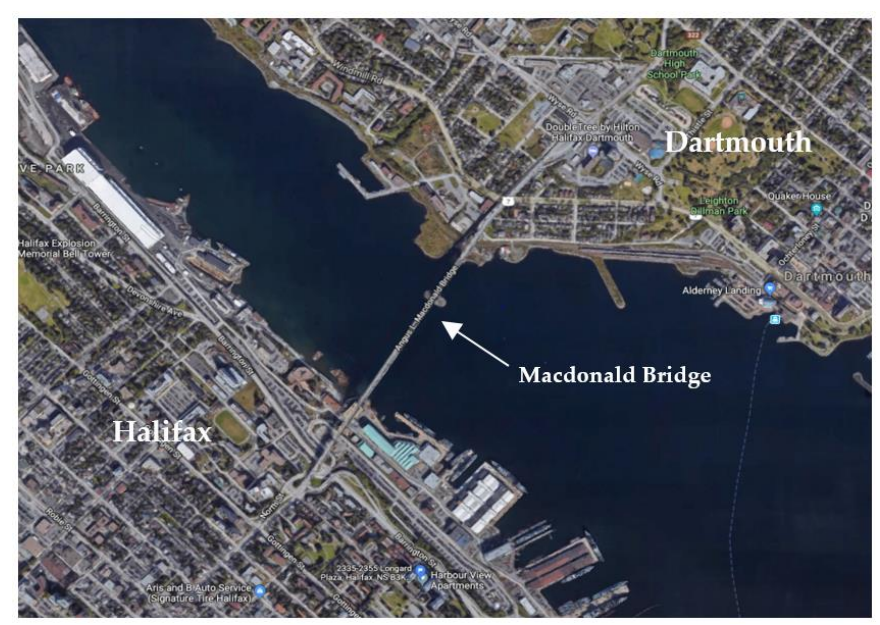

Figure 1. Macdonald Bridge with Halifax and Dartmouth on both sides.

The province of Nova Scotia adopted a sustainable transportation strategy to promote active transportation among the travelers. As a part of the strategy, we conducted the survey prior to the renewal event in 2013. The survey was distributed on the Macdonald Bridge during high traffic volume times over a seven-day period in June 2013. Pedestrians and cyclists crossing through the active transportation lanes were requested to stop and participate in a short intercept survey. 
Upon completion, they were given a complete survey package to take with them. The package contained a survey form and a pre-paid envelope, which could easily be filled out and returned. An online URL address of the survey was also included in the form. Respondents were instructed about their alternatives to fill out the paper survey or use the URL to complete the survey online. In addition, the survey was made available to the local libraries and bridge toll plazas. It was advertised on the DalTRAC blog, Facebook and Twitter pages, and featured in an article at a local magazine. An active transportation workshop was held by the Halifax Harbor Bridges, where the survey was filled out by the attendees. Furthermore, a \$50 CAD gift card was provided as an incentive to the respondents to participate at the survey. The survey had six separate sections that were designed to collect information about users' current travel behavior, household characteristics, demographics, and how they plan to coordinate their commute trips while active transportation is unavailable. The survey yielded a sample of 295 respondents. After data processing and cleaning, 261 surveys were found usable for further analysis.

\subsection{Data Preparation}

Preparation of the datasets included several processing steps. After the survey, data from the six sections were cleaned with caution and all identifiable information were replaced with codes. The sections of the survey included: (1) personal and household information; (2) daily commute trip; (3) weekly usage of the bridge by AT; (4) seasonal usage of the bridge by AT; (5) plans to accommodate AT trips for a temporary closure; and (6) opinion to support AT users during closure event. Independent variables used in the final models are extracted from the first four sections and dependent variables are obtained from section five and six. Below is a summary of data preparation for independent and dependent variables.

\subsubsection{Independent Variables}

A wide range of independent variables are considered in this study while developing the 'preference for alternative transportation services' and 'loyalty towards active transportation' models. Among them, the 'personal and household information' section of the survey is used to obtain the socio-demographic characteristics of the respondents. This includes age, annual income, employment status, number of vehicles owned, number of bicycles owned, etc. Respondents' primary commute mode, time, distance, reasons to use active transportation, average cycling and walking trips, etc. are extracted from section two, three and four, which are used as the travel attributes during model analysis. Furthermore, to understand the influence of respondents' residential location, various neighborhood characteristics are utilized in this study. To get the neighborhood information, at first home locations of the respondents from the survey are geocoded by an online service, BatchGeo. After that, using the coordinates and Halifax Regional Municipality (HRM) map, respondents' dissemination areas are identified in ArcGIS. This study uses the 2011 Canadian Census database and HRM Geodatabase that provide respondents' neighborhood information. After identifying the dissemination areas, respondents' home locations are joined with the census database to obtain dissemination area size, number of people, dwellings, single detached houses, apartments, employment rate, etc. in the neighborhood. Likewise, land use information, such as land use index, residential land use and commercial land use are derived from the land use database of HRM. A detailed description of the independent variables retained in the final models are presented in Table 1.

\subsubsection{Dependent Variables}

The survey presented a scenario to the Macdonald Bridge active transportation users that described the bridge closure event along with its active transportation lanes for an extended period. Respondents were asked about their preference during the closure event from a set of alternative transportation services, which were obtained through a public consultation workshop. The alternatives included: 
(1) Free shuttle services across Halifax Harbor for $24 \mathrm{~h}$ that would consist of 16 seat passenger shuttle buses with 12 bicycle racks on each bus;

(2) Frequent ferry services across Halifax Harbor that would provide one bicycle rack for users to take their bicycles on board, while using the free park and ride facility at the terminals;

(3) Frequent bus services across Halifax Harbor that would consist 35 seat passenger buses as well as 65 seat articulated buses with 2 bicycle racks on each bus, and

(4) Other services (e.g., free ferry services, allowing bicycles on bridge traffic lanes, etc.).

Table 1. Summary statistics of the independent variables.

\begin{tabular}{|c|c|c|c|}
\hline Variables & Description & Mean/Proportion & Standard Deviation \\
\hline \multicolumn{4}{|l|}{ Socio-demographic Characteristics } \\
\hline Male & If respondent is male $=1,0$ otherwise (binary variable) & $65.90 \%$ & - \\
\hline Middle age & $\begin{array}{l}\text { If respondent's age is between } 35 \text { to } 54 \text { years }=1, \\
0 \text { otherwise (binary variable) }\end{array}$ & $50.70 \%$ & - \\
\hline Age between 25 to 54 years & $\begin{array}{l}\text { If respondent's age is between } 25 \text { and } 54 \text { years }=1 \text {, } \\
0 \text { otherwise (binary variable) }\end{array}$ & $77.78 \%$ & - \\
\hline Lower income & $\begin{array}{l}\text { If respondent's annual income is below } \$ 40,000 \mathrm{CAD}=1 \text {, } \\
0 \text { otherwise (binary variable) }\end{array}$ & $21.23 \%$ & - \\
\hline Annual income $>\$ 40,000 \mathrm{CAD}$ & $\begin{array}{l}\text { If respondent's annual income is above } \$ 40,000 \mathrm{CAD}=1 \text {, } \\
0 \text { otherwise (binary variable) }\end{array}$ & $78.99 \%$ & - \\
\hline Full-time employment & $\begin{array}{l}\text { If respondent is full time employed }=1,0 \text { otherwise } \\
\text { (binary variable) }\end{array}$ & $72.54 \%$ & - \\
\hline Student & If respondent is a student $=1,0$ otherwise (binary variable) & $6.10 \%$ & - \\
\hline Car access & $\begin{array}{l}\text { If the respondent has car access }=1,0 \text { otherwise } \\
\text { (binary variable) }\end{array}$ & $50.68 \%$ & - \\
\hline No vehicle ownership & $\begin{array}{l}\text { If household does not own a private vehicle }=1 \text {, } \\
0 \text { otherwise (binary variable) }\end{array}$ & $74.33 \%$ & - \\
\hline No bicycle ownership & $\begin{array}{l}\text { If total number of bicycles in a household is zero }=1 \text {, } \\
0 \text { otherwise }\end{array}$ & $68.97 \%$ & - \\
\hline Number of bicycles $>4$ & $\begin{array}{l}\text { If total number of bicycles in the respondent's household } \\
\text { is more than } 4=1,0 \text { otherwise (binary variable) }\end{array}$ & $9.87 \%$ & - \\
\hline \multicolumn{4}{|l|}{ Travel Attributes } \\
\hline Primary commute mode_Auto & $\begin{array}{l}\text { If respondent's daily primary commute mode is auto }=1 \text {, } \\
0 \text { otherwise (binary variable) }\end{array}$ & $10.34 \%$ & - \\
\hline Primary commute mode_Transit & $\begin{array}{l}\text { If respondent's daily primary commute mode is transit }=1 \text {, } \\
0 \text { otherwise (binary variable) }\end{array}$ & $49.81 \%$ & - \\
\hline AT_Walking & $\begin{array}{l}\text { If respondent walk to cross the bridge for commuting } \\
\text { purpose }=1,0 \text { otherwise (binary variable) }\end{array}$ & $19.16 \%$ & - \\
\hline AT_Cycling & $\begin{array}{l}\text { If respondent cycle to cross the bridge for commuting } \\
\text { purpose }=1,0 \text { otherwise (binary variable) }\end{array}$ & $78.16 \%$ & - \\
\hline Commute travel time & Respondent's daily commuting time (minutes) & 32.69 & 14.99 \\
\hline Commute distance & Respondent's home to work location distance (kilometers) & 9.21 & 7.19 \\
\hline Commute distance $<20 \mathrm{~km}$ & $\begin{array}{l}\text { If respondent's daily commute distance is less than } 20 \mathrm{~km} \\
=1,0 \text { otherwise (binary variable) }\end{array}$ & $75.43 \%$ & - \\
\hline Reason for AT commute-Cost saving & $\begin{array}{l}\text { If the reason for daily AT use to commute is cost saving = } \\
1,0 \text { otherwise (binary variable) }\end{array}$ & $16.86 \%$ & - \\
\hline Reason for AT commute-Exercise & $\begin{array}{l}\text { If the reason for daily AT use to commute is exercise }=1 \text {, } \\
0 \text { otherwise (binary variable) }\end{array}$ & $44.83 \%$ & - \\
\hline Crossing frequency by bicycles (daily) & $\begin{array}{l}\text { If respondent daily crosses the bridge by bicycle for any } \\
\text { purpose }=1,0 \text { otherwise (binary variable) }\end{array}$ & $56.30 \%$ & - \\
\hline $\begin{array}{l}\text { Crossing frequency by bicycles } \\
(3-4 \text { times in a week })\end{array}$ & $\begin{array}{l}\text { If respondent crosses the bridge weekly } 3-4 \text { times by } \\
\text { bicycle for any purpose }=1,0 \text { otherwise (binary variable) }\end{array}$ & $26.10 \%$ & - \\
\hline Cycling frequency—work/education & $\begin{array}{l}\text { Respondent's weekly average one-way cycle trips for } \\
\text { work/education }\end{array}$ & 5.84 & 4.25 \\
\hline $\begin{array}{l}\text { Number of one-way walking trips in } \\
\text { winter season }\end{array}$ & $\begin{array}{l}\text { Respondent's one-way average walking trips during } \\
\text { Winter season }\end{array}$ & 23.03 & 51.51 \\
\hline
\end{tabular}


Table 1. Cont.

\begin{tabular}{cllc}
\hline Variables & \multicolumn{1}{c}{ Description } & Mean/Proportion & Standard Deviation \\
\hline Neighborhood Characteristics & & 38.970 & 36.300 \\
\hline Population density & $\begin{array}{l}\text { Population density in the neighborhood (per square } \\
\text { kilometer) }\end{array}$ & 20.543 & 20.952 \\
\hline Dwelling density & $\begin{array}{l}\text { Dwelling density in the neighborhood (per square } \\
\text { kilometer) }\end{array}$ & 44.80 & 30.20 \\
\hline Percentage of single detached house & Percentage of single detached house in the neighborhood & 37.65 & 30.96 \\
\hline Percentage of apartments & Percentage of apartments in the neighborhood & 41.91 & 30.35 \\
\hline Percentage of rental house & Percentage of rental house in the neighborhood & 29.16 & 24.60 \\
\hline Percentage of households with & $\begin{array}{l}\text { Percentage of households up-to } 4 \text { members in } \\
\text { neighborhood }\end{array}$ & 64.96 & 66.25 \\
\hline Employment rate & Employment rate in the neighborhood & 11.80 & 33.65 \\
\hline Percentage of residential land use & Percentage of residential land use in the neighborhood & 22.16 \\
\hline Percentage of commercial land use & Percentage of commercial land use & 0.19 \\
\hline Land use index & Land use index of the neighborhood & 0.17 \\
\hline
\end{tabular}

Exploratory analysis of the survey suggests that AT lane users prefer free shuttle service across the bridge most ( $41 \%)$, followed by more frequent ferry service (34\%). Some users want more frequent bus service $(10 \%)$ and other services $(15 \%)$, such as free transit passes, and additional park and ride facilities.

To examine the long-term behavioral impacts, the survey included questions on users' loyalty towards the active transportation modes. Respondents were asked to give their opinion on continuing to use active transportation modes during the closure event. Two types of active transportation users were observed during the survey.

(1) The first category consists of respondents who agree to start their travel by active transportation, and cross the harbor by any other mode during the closure event, which is considered to be the loyalty towards active transportation modes;

(2) The second category includes those who start traveling by other modes rather than active transportation, which is counted as a shift from active transportation modes.

Summary statistics shows that the majority of respondents (64\%) is found to be loyal to active transportation and continue walking and cycling during the temporary closure event. However, $28 \%$ of the users anticipate a shift from the usage of active transportation to other modes. About $8 \%$ are unsure of their anticipated travel behavior, which are excluded from further analysis.

\section{Modeling Approach}

This study follows a random utility-based discrete choice modeling approach, specifically, Random Parameter Logit (RPL) modeling technique, to develop the preference for alternative transportation service and loyalty towards active transportation models. Let, $U_{i j}$ is the utility derived from an alternative $i$ chosen by an individual $j$. This can be expressed as Equation (1):

$$
U_{i j}=\theta_{i j}+\beta_{j} X_{i j}+\varepsilon_{i j}
$$

where $\theta_{i j}$ is the alternate specific constant, $\beta_{j}$ is the estimable parameters, $X_{i j}$ is a column vector of the observed attributes and $\varepsilon_{i j}$ is the random error term. Conditional on $\beta_{j}$, the probability to choose an alternative $i$ by individual $j$ can be described as Equation (2):

$$
G_{j i}\left(\beta_{j}\right)=\exp \left(\theta_{i j}+\beta_{j}^{\prime} X_{i j}\right) / \sum_{i=1}^{I} \exp \left(\theta_{i j}+\beta_{j}^{\prime} X_{i j}\right)
$$

The traditional multinomial logit model is restricted to the IID assumption. However, due to different levels of adaptability and flexibility, it is possible that individuals possessing similar characteristics might not behave the same and could respond to a network disruption event differently 
than each other. Therefore, unobserved preference heterogeneity among individuals may occur. The study captures this heterogeneity by developing random parameter logit models that relax the restrictive assumption of homogeneity assumed by the traditional logit models [22]. The modeling structure anticipates heterogeneity by assuming a continuous distribution of the parameters $\left(\beta_{j}\right)$ across individuals. Since $\beta_{j}$ is random and unknown, random parameter logit probability is expressed through the integrals of standard logit probability (Equation (2)) over the density of parameters $\beta_{j}$. This paper assumes a normally distributed density function with mean $m$ and covariance $\sigma$. Thus, the choice probability of random parameter logit models can be written as Equation (3):

$$
P_{j i}=\int G_{j i}\left(\beta_{j}\right) f\left(\beta_{j} \mid m, \sigma\right) d \beta_{j}
$$

where, $f\left(\beta_{j} \mid m, \sigma\right)$ is the normally distributed density function. The log-likelihood function based on above probability expression can be described as Equation (4):

$$
L L=\sum_{j=1}^{J} \ln P_{j i}
$$

However, Equation (4) is a multivariate integral that does not have any closed form. Therefore, this study uses the Monte Carlo simulation to approximate the integral of the choice probability. The probabilities are approximated for any given value from the distribution. For each person, the choice probability $G_{j i}\left(\beta_{j}\right)$ is calculated for every $q$ draws. At first, a value of $\beta_{j}$ from $f\left(\beta_{j} \mid m, \sigma\right)$ is taken and identified it as $\beta_{j} q^{q \mid m, \sigma}$, which refers to the $q$-th draw from the density function. With this draw, the logit formula $G_{j i}\left(\beta_{j}{ }^{q \mid m, \sigma}\right)$ is calculated. The total process is repeated for $Q$ times. The integration over $f\left(\beta_{j} \mid m, \sigma\right)$ is approximated by averaging total $Q$ draws. This average is the simulated probability as shown in Equation (5):

$$
\bar{G}_{j i}=\frac{1}{Q} \sum_{q=1}^{Q} G_{j i}\left(\beta_{j}{ }^{q \mid m, \sigma}\right)
$$

Finally, the simulated probabilities are used to calculate the simulated log-likelihood, which can be given as Equation (6):

$$
S L=\sum_{j=1}^{J} \sum_{i=1}^{I} Y_{j i} \ln \frac{1}{Q} \sum_{q=1}^{Q} G_{j i}\left(\beta_{j}{ }^{q \mid m, \sigma}\right)
$$

where, $Y_{j i}$ takes the value 1 if an individual $j$ chooses an alternative $i, 0$ otherwise. SL is the simulated log-likelihood function. Instead of random draws, Halton sequence is used in this study since it requires substantial lower number of draws. The models are converged, and stable covariates are found at 250 Halton draws.

The model estimation process starts with developing skeleton models that include several policy variables. Both models are finalized after multiple iterations. While estimating the models, if the $t$-statistic of a parameter crosses the threshold value (1.64 as $90 \%$ confidence level), the parameter is considered in the final models. Along with $t$-statistics, the signs of the coefficients are observed as well to check whether they exhibit expected signs that is aligned with the priori hypothesis. The total procedure is performed until majority of the parameters exhibit statistical significance and goodness-of-fit measures of RPL models outperform the MNL models. Goodness-of-fit measures of the models are evaluated based on adjusted R-square, Akaike Information Criteria (AIC), and Bayesian Information Criteria (BIC). In both models, the RPL outperforms the traditional MNL as indicated by the higher adjusted R-square, and lower AIC and BIC values of RPL model.

\section{Result Discussion}

In both model specifications, most of the parameters are found to be statistically significant. However, few parameters are retained in the final model below the threshold $t$-statistic value. 
The underlying assumption here is, these parameters with asymptotic properties might show statistically significant relationships if a larger dataset were available. Moreover, they offer important behavioral insights and have critical policy implications. Furthermore, the results exhibit variations across the MNL and RPL models in case of some variables. These variations in RPL models are primarily identified as the presence of latent heterogeneity, which is captured through the mean and standard deviations of the random parameters. Below is a brief description of 'preference for alternative transportation services' and 'loyalty towards active transportation' model results.

\subsection{Preference for Alternative Transportation Services}

Table 2 shows the parameter estimation results of the preference for alternative transportation services model. A multinomial logit model is also presented in the table for comparison purpose. Below is a brief description of the model results.

Results suggest that higher-income individuals, who earn more than \$40,000 CAD annually, are less likely to prefer free shuttle services. Similarly, individuals with car access have lower probability to prefer the shuttle services. On the other hand, individuals who do not have vehicles in their households tend to prefer the free shuttle services. Individuals also have higher probability to prefer shuttle services while traveling by bicycles daily across the bridge. This perhaps indicate better bicycle-carrying facilities provided by the shuttle services to facilitate continued cycling trips. A positive relationship is observed between individuals who use AT for cost savings and the choice of shuttle services. Since shuttle service is a free-of-cost service, such individuals' higher probability of preferring shuttle services is plausible. Transit commuters exhibit lower propensity to prefer shuttle services as the transit routes bring them closer to their destinations without need for transfer. With the increase in percentage of apartments in the neighborhood, the tendency of preferring the shuttle mode also increases. Arguably, apartments generally house low to middle-income people who might like a free service compared to increased frequency of paid services.

Table 2. Parameter estimation results of Preference for Alternative Transportation Services.

\begin{tabular}{|c|c|c|c|c|}
\hline \multirow{2}{*}{ Variables } & \multicolumn{2}{|c|}{ Multinomial Logit } & \multicolumn{2}{|c|}{ Random Parameter Logi } \\
\hline & Coefficient & t-Stat & Coefficient & t-Stat \\
\hline \multicolumn{5}{|l|}{ Free shuttle services across the harbor } \\
\hline Constant & -1.7223 & -0.841 & -3.3910 & $-1.64 *$ \\
\hline Male & 2.2110 & $2.55^{* *}$ & 3.0559 & $3.37 * * *$ \\
\hline Annual income $>\$ 40,000 \mathrm{CAD}$ & -2.4564 & $-2.85^{* * *}$ & -4.1461 & $-2.65^{* * *}$ \\
\hline Car access & -0.8348 & -1.42 & -1.0443 & -1.50 \\
\hline No vehicle ownership & 1.7973 & $2.55 * *$ & 2.7856 & $2.89^{* * *}$ \\
\hline No bicycle ownership & -1.5868 & -1.32 & -2.1461 & -1.26 \\
\hline Primary commute mode_Transit & -0.6468 & -0.60 & -0.9752 & -0.76 \\
\hline Crossing frequency by bicycles (daily) & -1.2907 & -1.25 & 1.3724 & 1.08 \\
\hline Reason for AT commute-Cost saving & 0.0424 & 1.08 & 0.8927 & 1.14 \\
\hline Percentage of apartments & 0.0786 & $2.70 * * *$ & 0.1182 & $2.78^{* * *}$ \\
\hline Employment rate & 0.0085 & $3.20 * * *$ & 0.0181 & $3.03^{* * *}$ \\
\hline \multicolumn{5}{|l|}{ Frequent ferry services across the harbor } \\
\hline Constant & 3.2551 & $1.96 * *$ & 4.9739 & $2.17^{* *}$ \\
\hline Age between 25 to 54 years & 2.2882 & $3.25^{* * *}$ & 3.6559 & $2.68^{* * *}$ \\
\hline Annual income $>\$ 40,000 \mathrm{CAD}$ & 0.1547 & 0.21 & 0.6218 & 1.50 \\
\hline Car access & -1.1539 & -1.48 & -1.3975 & -1.40 \\
\hline No vehicle ownership & -1.6487 & $-1.90 *$ & -2.3291 & $-1.96^{* *}$ \\
\hline Primary mode for commuting-Auto & -2.6291 & $-2.08 * *$ & -3.2492 & $-1.72 *$ \\
\hline Primary mode for commuting-Transit & -2.5449 & $-1.61 *$ & -3.4770 & -1.14 \\
\hline Commute travel time & -0.0214 & -1.06 & -0.0373 & -1.25 \\
\hline AT_cycling & -0.6332 & -0.60 & -0.7991 & $-1.64 *$ \\
\hline Reason for AT commute-Exercise & -0.2926 & -0.51 & -0.9791 & -1.14 \\
\hline Crossing frequency by bicycles (daily) & -1.0030 & $-1.68^{*}$ & -1.5962 & $-1.90 *$ \\
\hline Population density & -0.2955 & -0.53 & 0.4853 & 0.50 \\
\hline Percentage of residential land use & 0.0116 & 1.26 & 0.0166 & $1.96^{* *}$ \\
\hline
\end{tabular}


Table 2. Cont.

\begin{tabular}{|c|c|c|c|c|}
\hline \multirow{2}{*}{ Variables } & \multicolumn{2}{|c|}{ Multinomial Logit } & \multicolumn{2}{|c|}{ Random Parameter Logi } \\
\hline & Coefficient & $t$-Stat & Coefficient & $t$-Stat \\
\hline \multicolumn{5}{|l|}{ Frequent bus services across the harbor } \\
\hline Constant & -0.6491 & -0.30 & -0.3754 & -1.42 \\
\hline Male & -0.4764 & -0.60 & -0.7315 & $-1.80 *$ \\
\hline Car access & -0.3791 & -0.45 & 0.6287 & $1.72 *$ \\
\hline No bicycle ownership & -2.5818 & -1.38 & 3.5802 & $1.64 *$ \\
\hline No vehicle ownership & -0.6653 & -0.66 & -1.0583 & $-1.97^{* *}$ \\
\hline Primary commute mode-Auto & 0.1709 & 1.17 & 0.4385 & 1.38 \\
\hline Primary commute mode-Transit & 0.8793 & 0.67 & 0.8503 & $1.64 *$ \\
\hline Commute distance $<20 \mathrm{~km}$ & 0.7160 & 0.44 & 0.5774 & $1.81 *$ \\
\hline Crossing frequency by bicycles (daily) & 0.4921 & 0.73 & 0.6840 & 0.94 \\
\hline Number of one-way walking trips in winter season & 0.0056 & $2.47^{* *}$ & 0.0096 & $3.01 * * *$ \\
\hline Dwelling density & -0.0176 & $-2.61 * * *$ & -0.0283 & $-3.10^{* * *}$ \\
\hline Percentage of households with 1 to 4 members & 0.0849 & $1.96 * *$ & 0.0905 & $1.69 *$ \\
\hline Percentage of residential land use & -0.2645 & -1.51 & -0.3499 & $-1.64 *$ \\
\hline \multicolumn{5}{|l|}{ Other services (reference) } \\
\hline Male & 0.2888 & 0.46 & 0.0914 & 1.12 \\
\hline No bicycle ownership & -1.7067 & -1.08 & -1.6577 & -0.92 \\
\hline Commute travel time & -0.0490 & $-2.54 * *$ & -0.0600 & $-2.64 * * *$ \\
\hline AT_Walking & 2.0521 & 1.51 & 2.4656 & $1.66 *$ \\
\hline Number of one-way walking trips in winter season & 0.0040 & $3.16^{* * *}$ & 0.0059 & $2.93^{* * *}$ \\
\hline Cycling frequency-work/education & 0.1827 & $2.31 * *$ & 0.2599 & $2.66^{* * *}$ \\
\hline Dwelling density & -0.0063 & $-1.78^{*}$ & -0.0097 & $-1.73 *$ \\
\hline \multicolumn{5}{|l|}{ Standard Deviations } \\
\hline Population density (frequent ferry services) & - & - & 0.0007 & $1.68 *$ \\
\hline Employment rate (free direct shuttle services) & - & - & 0.0143 & $2.05^{* *}$ \\
\hline \multicolumn{5}{|l|}{ Model Fits } \\
\hline LL Convergence & \multicolumn{2}{|c|}{-166.32} & \multicolumn{2}{|c|}{-160.39} \\
\hline Adjusted R-square & \multicolumn{2}{|c|}{0.450} & \multicolumn{2}{|c|}{0.512} \\
\hline AIC & \multicolumn{2}{|c|}{1.66} & \multicolumn{2}{|c|}{1.63} \\
\hline $\mathrm{BIC}$ & \multicolumn{2}{|c|}{2.28} & \multicolumn{2}{|c|}{2.23} \\
\hline
\end{tabular}

Notes: ${ }^{* * *} 99 \%$ confidence level; ${ }^{* *} 95 \%$ confidence level; $* 90 \%$ confidence level.

In case of more frequent ferry services, individuals aged between 25 and 54 tend to prefer frequent ferry service as a temporary service replacement during the disruption event. Also, higher-income individuals (i.e., annual income above $\$ 40,000 \mathrm{CAD}$ ) exhibit higher likelihood to prefer more frequent ferry services. However, the probability of more frequent ferry service preference decreases with individuals' access to households' cars. Presence of zero vehicle in households also decreases individuals' likelihood of preferring more frequent ferry services, rather they exhibit higher propensity to prefer free shuttle services as indicated by the positive coefficient value at $99 \%$ confidence level. As expected, the dummy variables representing individuals who commute primarily by auto and transit exhibit negative parametric values, which indicate their lower tendency to prefer more frequent ferry services. The findings are plausible since these individuals already have other travel alternatives available for commuting. In addition, since ferry is comparatively slower while crossing distance between Halifax and Dartmouth (which are connected through the Macdonald Bridge), individuals with longer commute time exhibit lower propensity to prefer ferry services during temporary intervention. They would take some other travel alternatives to compensate their added delays due to the active transportation lane closure. Individuals who use the active transportation for exercise purposes less likely favor more frequent ferry services. Arguably, riding the ferry does not fulfill their need for exercise, hence, they might shift their route elsewhere during the disruption event. Similar negative parameter is observed for individuals who use bicycles to cross the bridge daily, perhaps suggesting unavailability of enough space to carry bicycles on ferries. Living in the areas of higher population density, individuals are more likely to prefer frequent ferry services during the closure. Densely populated areas are near the ferry terminals on both Halifax and Dartmouth side. 
Approximate distances between Halifax downtown and Halifax ferry terminal is $1 \mathrm{~km}$, Dartmouth downtown and Dartmouth ferry terminal is $0.5 \mathrm{~km}$. Therefore, living nearby the ferry terminals might provide higher utility of ferry services to the pedestrians and cyclists while the active transportation lanes remain closed for an extended period. Male respondents demonstrate a lower tendency to prefer more frequent bus services during the network disruption event. Similarly, individuals from zero vehicle ownership households are less likely to prefer more frequent bus services. Such individuals also show lower probability to prefer frequent ferry services; however, they are found to have higher preference for the free-of-cost shuttle services. Perhaps these individuals are captive active transportation users who are more interested in a free service than increased frequency of paid services. As expected, transit commuters demonstrate a positive relationship, indicating their higher propensity to prefer more frequent bus services. The likelihood of preferring free shuttle services and frequent bus services are found lower for this particular group, which might suggest the pro-transit usage behavior of these individuals. Individuals who cross the bridge daily by bicycle also favor higher number of bus services during the closure event. Interestingly, such individuals exhibit a higher mean value for shuttle services (1.37) than the frequent bus services (0.68). This might be because shuttles offer higher number of bicycle racks on board than the buses. Hence, individuals who cross the bridge daily by bicycles exhibit higher tendency to prefer shuttle services than the frequent bus services. Finally, individuals living in the neighborhoods with higher percentage of residential land use exhibit lower likelihood of preferring frequent bus services, rather they tend to prefer more frequent ferry services during the closure event. Residential areas are situated farther away from the bridge where frequency of bus services may be lower. Therefore, individuals from residential areas might be more interested to drive to the ferry terminals, use the free park and ride option, and cross the distance between Halifax and Dartmouth using ferry services during the closure event. Although several variables in the RPL model of preference for alternative services are assumed to be random parameters, two neighborhood characteristics-population density (for more frequent ferry services) and employment rate in the neighborhood (for free shuttle services) - are found to exhibit statistically significant standard deviations.

\subsection{Loyalty towards Active Transportation}

Model results provide interesting insights about anticipated behavioral changes of active transportation (AT) users during the bridge closure event. More specifically, the study inquires whether pedestrians and cyclists would shift to other modes during an extended period pre-planned network disruption event. Please note that the alternative representing loyalty towards AT (i.e., no modal shift) is assumed to be reference category during estimation. In the model results, positive coefficient values represent the higher probability of shifting from current AT mode, which suggests lower likelihood of being loyal towards active transportation. On the other hand, negative coefficient values represent the opposite. A traditional multinomial logit model is estimated for comparison purposes. Table 3 shows the parameter estimation results of the random parameter logit model.

Middle age individuals are found more likely to be loyal to their active transportation mode during the temporary active transportation lane closure event. However, some middle age individuals might behave differently during the event, as indicated by the variable's higher standard deviation value than mean (standard deviation, 2.48; mean, 2.06). As expected, lower-income individuals, who earn less than $\$ 40,000$ CAD annually, tend to be loyal to the AT mode. Presence of higher number of bicycles (more than four) in the households also decreases individuals' probability to shift their mode. Arguably, these individuals may be captive bicycle users, hence, their loyalty towards using active transportation mode might not change depending on any condition. Surprisingly, students exhibit a positive relationship with the modal shift. Perhaps bicycle usage is higher in such student group because using AT lanes to cross the bridge during morning commute could save time. Closure of AT lane reduces such scope, which would result shifting from their current AT mode. 
In case of travel attributes, individuals' higher commute distance positively affects their modal shift. While traveling to distant work places, using the active transportation lanes of the bridge could save time during the peak hours. However, lane closure might add delay to such individuals' commuting. Hence, they exhibit less loyalty towards AT and would possibly switch to alternative modes to minimize the added delay during the closure event. As expected, higher propensity of being loyal to AT modes are observed for the individuals who frequently cross the bridge (daily and 3-4 times in a week) using bicycles. The variable representing 3-4 times weekly bridge crossing shows statistically significant standard deviation, which indicates behavioral variations across individuals. In addition, cost saving, a reason underlying the AT lane usage for commuting, increases the likelihood of being loyal to the active transportation modes as indicated by the negative coefficient value $(-1.19)$.

Table 3. Parameter Estimation Results of the Shifts in Mode by Active Transportation Users.

\begin{tabular}{|c|c|c|c|c|}
\hline \multirow{2}{*}{ Variables } & \multicolumn{2}{|c|}{ Multinomial Logit } & \multicolumn{2}{|c|}{ Random Parameter Logi } \\
\hline & Coefficient & t-Stat & Coefficient & t-Stat \\
\hline \multicolumn{5}{|l|}{ Socio-demographic Characteristic } \\
\hline Middle age & -1.2218 & $-1.83 * *$ & -2.0551 & $-3.53^{* * *}$ \\
\hline Lower income & -0.6375 & -1.04 & -1.6558 & -1.06 \\
\hline Student & 2.7419 & $2.59 * * *$ & 2.7806 & $2.78^{* * *}$ \\
\hline Number of bicycles $>4$ & -1.2128 & $-2.02 * *$ & -2.3492 & $-2.15^{* *}$ \\
\hline \multicolumn{5}{|l|}{ Travel Attributes } \\
\hline Commute distance & 0.0481 & $1.73 *$ & 1.9160 & $1.76^{*}$ \\
\hline Reason for AT commute-cost saving & 1.1228 & 1.49 & -1.1942 & $-1.65^{*}$ \\
\hline Crossing frequency by bicycles (daily) & -1.7275 & -1.62 & -2.1793 & $-1.64 *$ \\
\hline Crossing frequency by bicycles ( $3-4$ times in a week) & -2.6243 & $-1.99 * *$ & -2.6636 & $-2.35 * *$ \\
\hline \multicolumn{5}{|l|}{ Neighborhood Characteristics } \\
\hline Population density & -0.0257 & $-1.78 *$ & -0.1600 & $-2.19 * *$ \\
\hline Percentage of single detached house & 0.0507 & $1.69 *$ & 0.0598 & 1.48 \\
\hline Percentage of rental house & -0.0611 & $-3.06^{* * *}$ & -1.0617 & $-3.20 * * *$ \\
\hline Land use index & -2.0851 & -1.36 & -3.5579 & $-2.62 * * *$ \\
\hline Percentage of residential land use & -0.3770 & $-1.89 *$ & 0.3822 & $1.96 * *$ \\
\hline Percentage of commercial land use & 0.3129 & 1.14 & -1.4816 & -1.19 \\
\hline Employment rate & 0.1426 & 1.35 & 0.1444 & $2.91 * * *$ \\
\hline \multicolumn{5}{|l|}{ Standard Deviations } \\
\hline Middle age & - & - & 2.4824 & $2.73^{* * *}$ \\
\hline Crossing frequency (3-4 times in a week) & - & - & 0.2668 & $2.14^{* *}$ \\
\hline Population density & - & - & 0.8165 & $3.19^{* * *}$ \\
\hline Percentage of single detached house & - & - & 0.0044 & $2.56^{* * *}$ \\
\hline Employment rate & - & - & 0.6176 & $2.23^{* *}$ \\
\hline \multicolumn{5}{|l|}{ Model Fits } \\
\hline LL Convergence & \multicolumn{2}{|c|}{-70.865} & \multicolumn{2}{|c|}{-51.987} \\
\hline Adjusted R-square & \multicolumn{2}{|c|}{0.147} & \multicolumn{2}{|c|}{0.408} \\
\hline AIC & \multicolumn{2}{|c|}{1.10} & \multicolumn{2}{|c|}{0.94} \\
\hline $\mathrm{BIC}$ & \multicolumn{2}{|c|}{1.42} & \multicolumn{2}{|c|}{1.34} \\
\hline
\end{tabular}

Notes: *** 99\% confidence level; ** 95\% confidence level; * 90\% confidence level.

Among the neighborhood characteristics retained in the final model, land use index exhibits the highest impact. The land use index demonstrates a negative relationship with anticipated modal shift. This means, with the increase in land use index of the neighborhood, individuals' probability of being loyal towards active transportation modes increases. Higher mixed land use areas represent better designed neighborhoods with safe and convenient facilities for pedestrians and cyclists. Therefore, the finding that dwellers in such neighborhoods are more likely to be loyal to their active transportation modes during a temporary closure event, is plausible. Urban area dwellers also exhibit loyalty towards active transportation, as suggested by negative coefficient value of the variable representing population density. However, a statistically significant variance of 'population density' has been found during analysis, with the standard deviation higher than mean. This heterogeneity indicates that the effect of living in densely populated areas varies among individuals, possibly due to availability of various 
travel alternatives in urban areas. In addition, individuals living in neighborhoods with a higher percentage of rental houses are less likely to shift away from AT modes. Perhaps they are the captive AT user group, hence, loyal to AT. Suburban dwellers, on the other hand, are found to be less loyal and have higher likelihood to shift their mode from active transportation. For instance, individuals living in the neighborhoods with higher percentage of single detached houses and residential land use exhibit positive relationships with anticipated modal shift. Arguably, these individuals have fewer economic restrictions and might have alternative travel arrangements, which could be used during the closure event. However, 'percentage of single detached house' shows a statistically significant standard deviation at $1 \%$ significance level, which suggests the existence of variations in loyalty among individuals living in neighborhoods with higher percentage of single detached houses. Higher employment rate in the neighborhood also increases individuals' tendency to shift from their current active transportation mode during the network disruption. Interestingly, a statistically significant variance at $95 \%$ confidence level is observed for the variable 'employment rate', with the standard deviation higher than the mean (standard deviation, 0.62; mean, 0.14). This suggests that living in the neighborhoods with higher employment rate might not increase all individuals' probability to shift modes, rather some individuals would exhibit their loyalty towards AT during the closure event. Variable representing the percentage of commercial land use in the neighborhood has negative impact on individuals' modal shift. Commercial (e.g., retail and business) areas offer better active transportation facility since it enhances the overall business prospects [23]. Hence, individuals living in such neighborhood tend to be loyal towards active transportation modes.

\section{Conclusions}

This paper presents a comprehensive investigation of the anticipated travel behavior of active transportation users during a major transportation infrastructure renewal project. It significantly contributes in the literature by providing an in-depth understanding of the active transportation users' preferences for alternative transportation services and loyalty towards walking and cycling, given that the active transportation lanes of a critical infrastructure remain closed for an extended period. A random parameter logit (RPL) modeling technique is employed in this study that examines the effects of a wide range of socio-demographic characteristics, travel attributes and neighborhood characteristics on active transportation users' preferences and loyalty during the disruption event.

Model results suggest that higher-income individuals, who earn more than $\$ 40,000$ CAD annually, have lower propensity to prefer free shuttle services. Rather, they are more likely to prefer frequent ferry services during the closure event. Also, living in the neighborhoods with higher residential land use percentage increases individuals' probability to prefer frequent ferry services. On the other hand, individuals who do not own a vehicle and use active transportation modes for cost saving, tend to prefer free shuttle services. In case of the frequent bus services, higher likelihood is observed for the transit commuters. In addition, zero bicycle ownership and higher number of walking trips during winter season increase individuals' tendency of preferring frequent bus services. These findings would assist the policy makers to adopt relevant strategies that support to implement alternative transportation services during active transportation lane closure of a major transportation network. Results exhibit different service preferences by different types of people. Therefore, policy makers should focus on developing a set of measures by considering the market segmentations, which would satisfy travel needs for all during such disruption events. For instance, as an alternative of commuting, 'work-from-home' strategy could be implemented since individuals with higher commuting time are found not to prefer any of the proposed alternatives during the closure event.

In case of loyalty towards active transportation modes, results indicate that higher mixed land use area dwellers tend to be loyal towards active transportation during the temporary closure event. Also, higher number of bicycles in households and higher population density in the neighborhood increase individuals' likelihood of being loyal to the active transportation modes. Such findings are expected to assist the smart growth of a community that supports creating better 
designed neighborhoods with sustainable transportation infrastructures (e.g., safe, convenient and well-maintained cycling and walking lanes). Policy measurements should also be developed for the individuals who exhibit high possibility to shift away from their current active transportation modes. For example, students exhibit higher probability to shift from current active transportation mode during the closure event. Individuals living in the neighborhoods of higher single detached houses and higher residential land use share also tend to shift their mode. Therefore, to advance the sustainable transportation planning agenda, target marketing and/or comprehensive social marketing initiatives could be adopted to restrain such users' long-term behavioral shift. In addition, results of this study indicate the existence of taste preference variations across individuals. Hence, policy interventions should be flexible enough to attain better outcomes for all types of active transportation users.

The paper contributes to the current literature in many ways. Specifically, it offers critical understanding of the factors affecting the loyalty of the cyclists and pedestrians in response to a temporary closure of a major transportation infrastructure along with its active transportation lane. Analysis of the proposed alternative services provides valuable information to better prepare for any situations that might require closing major transportation networks for an extended period.

Author Contributions: Conceptualization, M.A.H.; Data curation, N.A.K.; Formal analysis, N.A.K.; Funding acquisition, M.A.H.; Investigation, N.A.K.; Methodology, N.A.K.; Project administration, N.A.K. and M.A.H.; Resources, N.A.K. and M.A.H.; Software, N.A.K.; Supervision, M.A.H.; Validation, N.A.K.; Writing—original draft, N.A.K.; Writing—review \& editing, N.A.K. and M.A.H.

Funding: This research received no external funding.

Acknowledgments: The authors would like to thank Natural Sciences and Engineering Research Council (NSERC) of Canada, Nova Scotia Department of Energy, Halifax Regional Municipality and Halifax Harbor Bridges for their contribution in supporting the research. The authors also would like to thank Siobhan Witherbee, Dillon Coyle and Mahmudur Rahman Fatmi for their assistance in data preparation and literature review.

Conflicts of Interest: The authors declare no conflict of interest.

\section{References}

1. Xie, F.; Levinson, D. Evaluating the Effects of the I-35W Bridge Collapse on Road-Users in the Twin Cities Metropolitan Region. Transp. Plan. Technol. 2011, 34, 691-703. [CrossRef]

2. Zhu, S.; Tilahun, N.; Levinson, D.; He, X. Planned Versus Unplanned: Travel Impacts and Adjustment Strategies of the Collapse and the Reopening of I-35W Bridge. SSRN 2009. [CrossRef]

3. Tilahun, N.; Levinson, D. I-35W Bridge Collapse: Travel Impacts and Adjustment Strategies. Available online: https:// core.ac.uk/download/pdf/6836368.pdf (accessed on 30 March 2018).

4. Danczyk, A.; Liu, H. Unexpected Cause, Unexpected Effect: Empirical Observations of Twin Cities Traffic Behavior after the I-35W Bridge Collapse and Reopening. In Proceedings of the 89th Annual Meeting of Transportation Research Board, Washington, DC, USA, 10-14 January 2010.

5. Hunt, J.; Brownlee, A.; Stefan, K. Responses to Centre Street Bridge Closure: Where the "Disappearing" Travelers Went. Transp. Res. Rec. J. Transp. Res. Board 2002, 1807, 51-58. [CrossRef]

6. Clegg, R. Empirical Studies on Road Traffic Response to Capacity Reduction. Transp. Traffic Theory 2007, 17, $155-178$.

7. Giuliano, G.; Golob, J. Impacts of the Northridge Earthquake on Transit and Highway Use. J. Transp. Stat. 1998, 1, 1-20.

8. Mueller, N.; Rojas-Rueda, D.; Cole-Hunter, T.; de Nazelle, A.; Dons, E.; Gerike, R.; Götschi, T.; Panis, L.I.; Kahlmeier, S.; Nieuwenhuijsen, M. Health Impact Assessment of Active Transportation: A Systematic Review. Prev. Med. 2015, 76, 103-114. [CrossRef] [PubMed]

9. Zhu, S.; Levinson, D.; Liu, H.X.; Harder, K. The Traffic and Behavioral Effects of the I-35W Mississippi River Bridge Collapse. Transp. Res. Part A Policy Pract. 2010, 44, 771-784. [CrossRef]

10. Dahlgren, J. The Effects of Reconstruction of I-880 on Travel Behavior. In Proceedings of the 81st Annual Meeting of Transportation Research Board, Washington, DC, USA, 13-17 January 2002.

11. Chang, S.; Nojima, N. Measuring Post-disaster Transportation System Performance: The 1995 Kobe Earthquake in Comparative Perspective. Transp. Res. Part A Policy Pract. 2001, 35, 475-494. [CrossRef] 
12. Wesemann, L.; Hamilton, T.; Tabaie, S.; Bare, G. Cost-of-Delay Studies for Freeway Closures Caused by Northridge Earthquake. Transp. Res. Rec. J. Transp. Res. Board 1996, 1559, 67-75. [CrossRef]

13. Faturechi, R.; Miller-Hooks, E. Measuring the Performance of Transportation Infrastructure Systems in Disasters: A Comprehensive Review. J. Infrastruct. Syst. 2014, 21, 04014025. [CrossRef]

14. Hensher, D.A.; Brewer, A.M. Going for Gold at the Sydney Olympics: How Did Transport Perform? Transp. Rev. 2002, 22, 381-399. [CrossRef]

15. Karlaftis, M.G.; Kepaptsoglou, K.; Stathopoulos, A.; Dimitriou, D. Public Transportation during the Athens 2004 Olympics: From Planning to Performance Evaluation. In Proceedings of the 85th Annual Meeting of Transportation Research Board, Washington, DC, USA, 22-26 January 2006.

16. Lo, S.; Hall, R.W. Effects of the Los Angeles Transit Strike on Highway Congestion. Transp. Res. Part A Policy Pract. 2006, 40, 903-917. [CrossRef]

17. Van Exel, N.J.A.; Rietveld, P. Public Transport Strikes and Traveller Behaviour. Transp. Policy 2001, 8, 237-246. [CrossRef]

18. Lai, W.T.; Chen, C.F. Behavioral Intentions of Public Transit Passengers-The Roles of Service Quality, Perceived Value, Satisfaction and Involvement. Transp. Policy 2011, 18, 318-325. [CrossRef]

19. Disney, J. Customer Satisfaction and Loyalty: The Critical Elements of Service Quality. Total Qua. Manag. 1999, 10, 491-497. [CrossRef]

20. Hoang-Tung, N.; Kojima, A.; Kubota, H. Recognising Customers' Patterns of Bus Service Patronage Using a Loyalty Framework. IATSS Res. 2014, 37, 148-156. [CrossRef]

21. Wegman, F.; Aarts, L.; Bax, C. Advancing Sustainable Safety: National Road Safety Outlook for the Netherlands for 2005-2020. Saf. Sci. 2008, 46, 323-343. [CrossRef]

22. Train, K.E. Discrete Choice Methods with Simulation; Cambridge University Press: Boston, MA, USA, 2002.

23. Transport Canada. Available online: http://publications.gc.ca/site/eng/393953/publication.html (accessed on 31 March 2018).

(C) 2018 by the authors. Licensee MDPI, Basel, Switzerland. This article is an open access article distributed under the terms and conditions of the Creative Commons Attribution (CC BY) license (http://creativecommons.org/licenses/by/4.0/). 